Egyptian J. Anim. Prod., (2004) 41(2):73-84 |

\title{
GROWTH CHARACTERISTICS OF ROMANOV ROMANOV-RAHMANI CROSSBRED LAMBS IN EGYPT
}

AND

\author{
M. A. Elshennawy ${ }^{1}$, H. Almahdy ${ }^{2}$ and Mona A. Osman ${ }^{2}$ \\ 1- Department of Animal Production, Faculty of Agriculture, South of Valley \\ University, Sohag, Egypt, 2- Sheep and Goat Research Department, Animal \\ Production Research Institute, Ministry of Agriculture and Land Reclamation, \\ Dokki, Giza, Egypt
}

\section{SUMMARY}

Sheep growth characteristics as affected by breed group (Romanov, 1/2Rahmanil/2Romanov and 3/4Rahmanil/4Romanov) and non-genetic factors (sex, season of birth, year of birth, type of birth, dam age and number of weights) were studied.

Monthly weights were used to calculate growth curve parameters for each lamb using Brody's growth function $Y_{l}=A\left(l-B e^{-K_{t}}\right)$. Its derivatives in terms of instantaneous average growth rate (IGR) and amount of maturity remaining to be attained as a fraction of the weight already attained (AMRA) were estimated at 2, 6 and 12 months of age.

Least squares means for the growth curve parameters $A, B$ and $K$ were 44.26 , 0.955 and 0.004 , respectively, and their derivatives at 2, 6 and 12months of age were, respectively, $118,69,35 \%$ for $I G R$ and $3.82,1.22$ and 0.47 for AMRA. $R^{2}$ was estimated as $98.9 \%$. There were no significant effect of breed group on all studied growth characteristics except IGR at 6 month of age. The effect of sex was significant $(P<0.01)$ only for $A, B$ and for IGR at all ages. Season of birth had significant effect only on $B(P<0.01)$ and only on IGR at 6 months and $A M R A$ at 2 months $(P<0.05)$. All growth characteristics were significantly $(P<0.01)$ affected by year of birth and significantly $(P<0.05)$ influenced by type of birth except $A$ and IGR at 6 months. Age of dam did not show any significant effect on $A, B$ or $K$ and had significant $(P<0.01)$ effect only at 2 months on IGR and AMRA and at 6 months on IGR.

Keywords: Growth, nonlinear growth function, Rahmani, Romanov, crossbred growth and maturity characteristics

\section{INTRODUCTION}

Growth is a complex biological process that must be evaluated carefully to determine the suitably economic marketing time and to plan and monitor the appropriate management and genetic improvement programs. Knowledge relating mature weight to both birth weight and growth rate of various breed groups used for meat production should enable producers to select breeds with the most efficient growth patterns.

Issued by The Egyptian Society of Animal Production 
Growth characteristics of lambs of Egyptian breeds (Rahmani, Ossimi and Barki) and their crosses with Finnsheep have been extensively studied (e.g. Mousa, 1989; Mokhtar et al., 1991; Elshennawy et al., 1998 and El-Wakil, 2004). Corresponding information on Romanov crosses have yet to be investigated.

Romanov sheep was first imported to Egypt from France by the Ministry of Agriculture in 1985. A crossbreeding program involving this breed was implemented to improve the productivity of Rahmani sheep in Mahallet Mousa Experimental Station. Growth data on pure Romanov (R), 1/2Rahmani $1 / 2$ Romanov (1/2 R) and 3/4Rahmani 1/4 Romanov (1/4R) lambs were collected and used in the present study.

The objective of the study was to analyze these data to obtain growth curve parameters and their derivatives for lambs as influenced by breed group and non genetic factors, namely, sex, season of birth, type of birth, dam age and number of weights.

\section{MATERIAL AND METHODS}

Data:

In this study data were collected during the years from 1985 to 1998 from sheep flocks raised at Mahallet Mousa Experimental Farm (North Delta) belonging to the Egyptian Ministry of Agriculture situated in northern Delta. A total number of 1693 lambs [ 136 Romanov, $782 \quad 1 / 2 R$ and $775 \quad 1 / 4 R$ ] were available for the present study. The data represent monthly weights on both male and female lambs starting at birth. Only data from lambs with 12 or more consecutive weights were included in the analysis. An accelerated lambing system of three matings per two years was practiced. For Romanov crossbred ewes, mating seasons were May, January and September, while Romanov ewes entered one mating season per year in September. Ewes and rams were first mated at about 18 months of age. Lambs were weaned at about two months of age. Animals were sheared twice a year, in March and September. Lambs were crept from the fifth week of age till weaning on a concentrate ration ( $83 \%$ corn, $15 \%$ soybean, $2 \%$ salts and vitamins). From weaning to yearling age, crossbred lambs were fed on concentrate feed mixture $(35 \%$ corn, $30 \%$ undecorticated cotton seed cake, $25 \%$ wheat bran, $6 \%$ molasses, $3 \%$ limestone and $1 \%$ mineral salts) together with corn, berseem hay, wheat bran and soybean, in quantities proportional to lambs weights. Animals were allowed to drink twice or thrice a day.

\section{Growth function parameters:}

Among the nonlinear growth models, Brody's function (Brody, 1945) was used to fit individual data as its validity in fitting growth curves has been already demonstrated in Egyptian literature (Mousa, 1989; Mokhtar et al., 1991 and Elshennawy et al., 1998).

In Brody's function $\mathrm{Y}_{\mathrm{t}}=\mathrm{A}\left(1-\mathrm{Be}^{-\mathrm{Kt}}\right), \mathrm{Y}_{1}$ is the observed weight of lamb at age $\mathrm{t}$ in days, $\mathrm{A}$ is the asymptotic weight, $\mathrm{B}$ is the parameter related to early life weight changes in body weight and provided for a Y-intercept term, e is the base of natural logarithms (2.30259) and $\mathrm{K}$ is the parameter indicating general rate of maturing or growth rate relative to mature weight. As $\mathrm{K}$ values are function of growth rates relative to mature weight they should only be used as indicators to compare growth rates of individual animals whose A values are equal (McCurtey et al., 1984). Larger K values characterize 
earlier maturing animals. The coefficient of determination $\left(\mathrm{R}^{2}\right)$ was calculated for each animal as a goodness of fit criterion.

Different and similar mature weights combined with different and similar maturing rates create various patterns of growth. Examples of combinations of A and $\mathrm{K}$ which were chosen to show the between sex within breed variability in growth patterns are presented in Table 1 . Animals with different $\mathrm{A}$ values showed different or similar $\mathrm{k}$ values, and those with similar $\mathrm{A}$ values presented different or similar $\mathrm{K}$ values. According to brown et al. 1972, only when two animals are growing to similar mature weights, can $\mathrm{K}$ be considered as a measure of differences in growth rate, otherwise, $\mathrm{K}$ measures differences in growth rate relative to mature size. Different patterns of growth are attained when two animals have similar mature weights but different $\mathrm{K}$ values or similar $\mathrm{K}$ values but different mature weights. Different mature weights and different $\mathrm{K}$ values may or may not represent different patterns of growth. A larger mature weight accompanied by a small $\mathrm{K}$ value is unlikely to present a growth pattern different than a small mature weight with a large $\mathrm{K}$ value (Brown et al., 1972).

\section{Derivatives of growth parameters:}

Brody (1945) defined the instantaneous growth rate $\left(\mathrm{IGR}_{\mathrm{t}}\right)$, as dy $/ \mathrm{dt}=\mathrm{Ky} \mathrm{y}_{\mathrm{t}}\left(\mathrm{Be} \mathrm{e}^{-\mathrm{Kt} / 1}\right.$ $\mathrm{Be}^{-\mathrm{Kt}}$ ). The IGR, was calculated for each animal at 2 (IGR2), 6 (IGR6) and 12 (IGR12) months of age.

According to Brown et al. (1976), the expression (A-Y, $/ Y_{t}$ represents the amount of maturity (in weight) remaining to be attained as a fraction of the maturity (in weight) already attained at any age $\left(\mathrm{AMRA}_{\mathrm{L}}\right)$. The $\mathrm{AMRA}$, was calculated for each animal at 2 (AMRA2), 6 (AMRA6) and 12 (AMRA12) months of age.

\section{Statistical analysis:}

Data were analyzed, using a least squares fixed linear model by Harvey's Mixed Model (1990), to estimate the least squares means for the breed group effect, the non-genetic effects (sex, season of birth, year of birth, type of birth, age of the dam, number of observed weights) and the first order interaction effects among these factors for growth parameters and their derivatives $\left(\mathrm{IGR}_{t}\right.$ and $\left.\mathrm{AMRA}_{t}\right)$. Individual estimates were obtained using the nonlinear procedure (NLIN) of SAS packages (SAS, 1988).

An average growth pattern for three lambs from the studied breed groups is presented in Figure 1. 
Table 1. Combinations of mature weight (A) and rate of maturing (K) representing different growth patterns in Romanov, 1/2 Romanov and 1/4 Romanov males and females

\begin{tabular}{|c|c|c|c|c|}
\hline \multirow[b]{3}{*}{ Breed } & \multicolumn{4}{|c|}{ Sex } \\
\hline & \multicolumn{2}{|c|}{ Males } & \multicolumn{2}{|c|}{ Females } \\
\hline & $\mathrm{A}(\mathrm{kg})$ & K & $\mathrm{A}(\mathrm{kg})$ & $\mathbf{K}$ \\
\hline \multirow[t]{8}{*}{ Romanov } & 36.15 & 0.0015 & 31.12 & 0.0038 \\
\hline & 36.37 & 0.0054 & 31.64 & 0.0051 \\
\hline & 36.42 & 0.0035 & 64.15 & 0.0011 \\
\hline & 57.66 & 0.0035 & 47.30 & 0.0011 \\
\hline & 43.43 & 0.0027 & 36.58 & 0.0052 \\
\hline & 43.82 & 0.0027 & 36.36 & 0.0052 \\
\hline & 56.95 & 0.0057 & 36.38 & 0.0042 \\
\hline & 34.91 & 0.0083 & 65.55 & 0.0016 \\
\hline \multirow[t]{8}{*}{ 1/2Romanov } & 30.06 & 0.0070 & 30.45 & 0.0040 \\
\hline & 30.30 & 0.0035 & 30.29 & 0.0072 \\
\hline & 53.81 & 0.0013 & 82.63 & 0.0009 \\
\hline & 83.03 & 0.0013 & 55.58 & 0.0009 \\
\hline & 30.68 & 0.0063 & 30.29 & 0.0070 \\
\hline & 30.73 & 0.0068 & 30.29 & 0.0072 \\
\hline & 89.16 & 0.0012 & 47.81 & 0.0029 \\
\hline & 41.32 & 0.0054 & 34.57 & 0.0052 \\
\hline \multirow[t]{8}{*}{ 1/4Romanov } & 31.88 & 0.0071 & 30.33 & 0.0078 \\
\hline & 31.88 & 0.0035 & 30.37 & 0.0033 \\
\hline & 52.31 & 0.0012 & 49.05 & 0.0014 \\
\hline & 87.82 & 0.0012 & 62.31 & 0.0014 \\
\hline & 30.28 & 0.0068 & 30.08 & 0.0056 \\
\hline & 30.57 & 0.0062 & 30.26 & 0.0056 \\
\hline & 40.92 & 0.0037 & 41.31 & 0.0046 \\
\hline & 88.54 & 0.0011 & 61.14 & 0.0014 \\
\hline
\end{tabular}

The estimates of $\mathrm{A}, \mathrm{B}$ and $\mathrm{K}$ were used to predict weights from 0 to 18 months of age. Weighs predicted, though affected by errors in the original measures and errors of estimation of $\mathrm{A}, \mathrm{B}$ and $\mathrm{K}$, represent weights similar to actual weights (Figure 1) with the effects of temporary environment and errors averaged out. The predicted weight-age pattern is suppose to be more useful than actual weights in describing the pattern of relationships among growth measurements (Brown et al, 1972). 

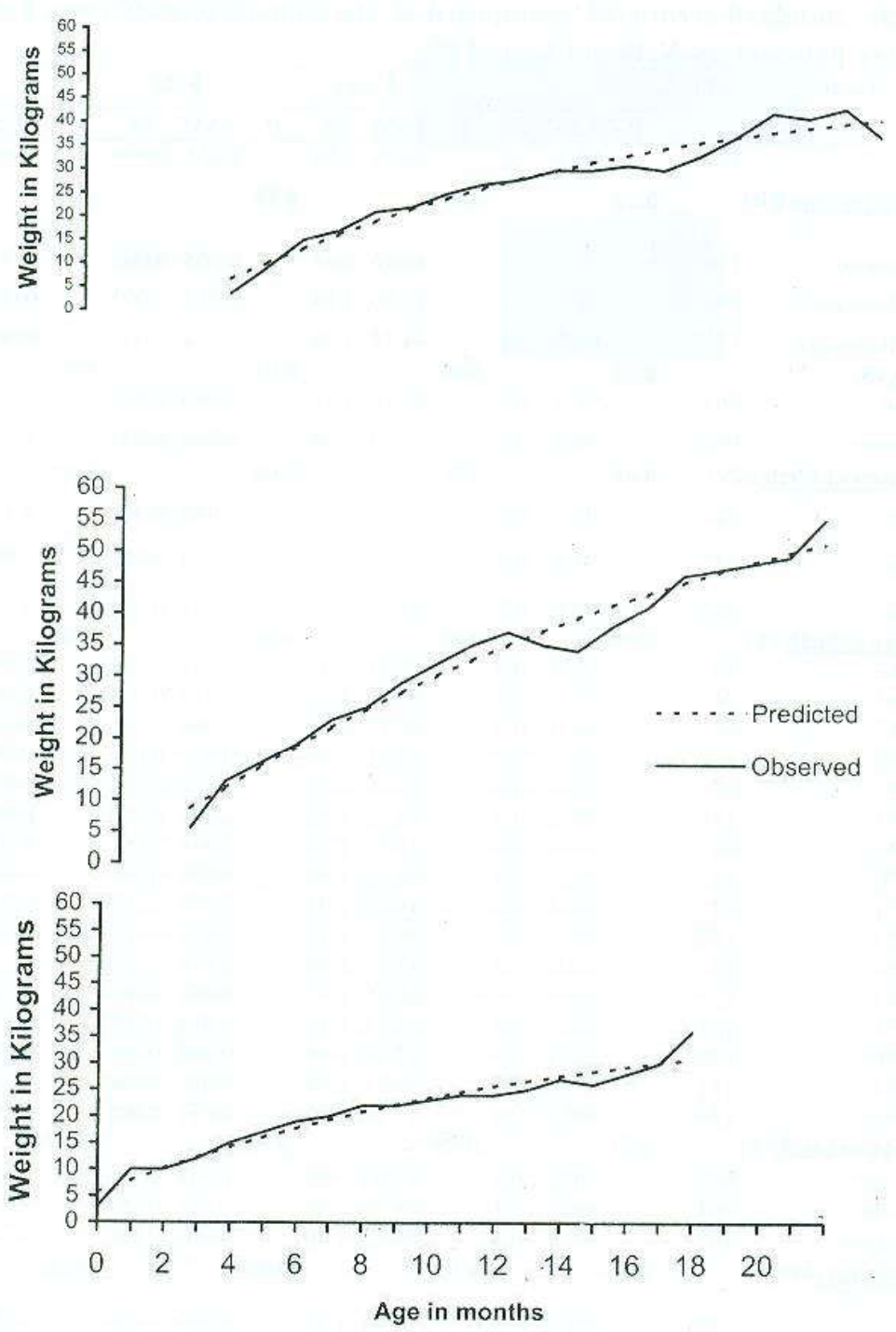

Figure 1. Brody's function fitted to observed weights for Romanov, $1 / 2$ Romanov and 1/4 Romanov

\section{RESULTS AND DISCUSSION}

\section{Growth parameters:}

The mean least-squares estimates and their standard errors of growth curve parameters are shown in Table 2. 
Table 2. The probability of type I error (P), least squares means (LSM) and their standard errors (SE) computed of the main factors affecting Brody growth curve parameters $\mathrm{A}, \mathrm{B}$ and $\mathrm{K}$, and $\mathrm{R}^{2}$

\begin{tabular}{|c|c|c|c|c|c|c|c|c|c|c|c|c|c|}
\hline \multirow[t]{2}{*}{ Factor } & \multirow[t]{2}{*}{ No. } & \multicolumn{4}{|c|}{$\mathrm{R}^{2}$} & \multicolumn{2}{|c|}{$\mathrm{A}(\mathrm{kg})$} & \multicolumn{4}{|c|}{$\mathrm{B}(\mathrm{kg})$} & \multicolumn{2}{|c|}{ K } \\
\hline & & $\mathrm{P}$ & LSM & $\mathrm{SE}$ & $\mathrm{P}$ & LSM & SE & $\mathrm{P}$ & LSM & SE & $\mathrm{P}$ & LSM & $\mathrm{SE}$ \\
\hline$\mu$ & 1693 & & 98.9 & 0.2 & & 44.26 & 1.54 & & 0.955 & 0.004 & & 0.00419 & 0.00027 \\
\hline Breed group $(B R)$ & & 0.22 & & & 0.85 & & & 0.72 & & & 0.94 & & \\
\hline Romanov & 136 & & 99.2 & 0.3 & & 44.16 & 2.44 & & 0.958 & 0.007 & & 0.00426 & 0.00042 \\
\hline 1/2Romanov & 782 & & 98.7 & 0.1 & & 43.90 & 1.14 & & 0.952 & 0.003 & & 0.00412 & 0.00020 \\
\hline I/4Romanov & 775 & & 98.8 & 0.1 & & 44.72 & 1.04 & & 0.954 & 0.003 & & 0.00419 & 0.00018 \\
\hline$\underline{\operatorname{Sex}}(S)$ & & 0.61 & & & 0.00 & & & 0.01 & & & 0.90 & & \\
\hline$\overline{\text { Male }}$ & 763 & & 98.9 & 0.1 & & 47.12 & 1.12 & & 0.960 & 0.003 & & 4.18 & 0.19 \\
\hline Female & 930 & & 98.9 & 0.2 & & 41.39 & 1.29 & & 0.950 & 0.004 & & 4.21 & 0.22 \\
\hline Season of birth & $(\mathrm{SN})$ & 0.49 & & & 0.56 & & & 0.00 & & & 0.09 & & \\
\hline Feb. & 744 & & 98.9 & 0.1 & & 43.63 & 1.04 & & 0.950 & 0.003 & & 4.47 & 0.18 \\
\hline June & 533 & & 98.8 & 0.2 & & 45.33 & 1.58 & & 0.950 & 0.005 & & 3.89 & 0.27 \\
\hline Oct. & 386 & & 99.0 & 0.2 & & 43.82 & 1.52 & & 0.964 & 0.004 & & 4.21 & 0.26 \\
\hline Year of birth (Y) & & 0.00 & & & 0.00 & & & 0.00 & & & 0.00 & & \\
\hline 1983 & 38 & & 99.0 & 0.3 & & 52.74 & 2.47 & & 0.943 & 0.007 & & 0.00309 & 0.00043 \\
\hline 1984 & 74 & & 99.1 & 0.2 & & 42.17 & 1.82 & & 0.939 & 0.005 & & 0.00525 & 0.00031 \\
\hline 1985 & 47 & & 99.0 & 0.3 & & 48.77 & 2.23 & & 0.968 & 0.006 & & 0.00334 & 0.00039 \\
\hline 1986 & 137 & & 98.4 & 0.2 & & 40.61 & 1.48 & & 0.975 & 0.004 & & 0.00472 & 0.00026 \\
\hline 1987 & 67 & & 99.0 & 0.2 & & 42.87 & 2.01 & & 0.959 & 0.006 & & 0.00392 & 0.00035 \\
\hline 1988 & 141 & & 99.2 & 0.2 & & 40.83 & 1.48 & & 0.932 & 0.004 & & 0.00365 & 0.00026 \\
\hline 1989 & 69 & & 99.0 & 0.2 & & 41.59 & 1.98 & & 0.948 & 0.006 & & 0.00371 & 0.00034 \\
\hline 1990 & 85 & & 98.9 & 0.2 & & 46.58 & 1.70 & & 0.930 & 0.005 & & 0.00393 & 0.00029 \\
\hline 1991 & 78 & & 99.2 & 0.2 & & 41.39 & 1,95 & & 0.945 & 0.006 & & 0.00446 & 0.00034 \\
\hline 1992 & 184 & & 99.3 & 0.2 & & 48.12 & 1.39 & & 0.934 & 0.004 & & 0.00311 & 0.00024 \\
\hline 1993 & 87 & & 99.0 & 0.2 & & 43.45 & 1.90 & & 0.938 & 0.005 & & 0.00406 & 0.00033 \\
\hline 1994 & 151 & & 96.9 & 0.2 & & 41.55 & 1.37 & & 0.983 & 0.004 & & 0.00484 & 0.00024 \\
\hline 1995 & 102 & & 99.1 & 0.2 & & 40.43 & 1.56 & & 0.985 & 0.005 & & 0.00503 & 0.00027 \\
\hline 1996 & 148 & & 99.0 & 0.2 & & 42.39 & 1.40 & & 0.966 & 0.004 & & 0.00476 & 0.00024 \\
\hline 1997 & 151 & & 99.3 & 0.2 & & 46.93 & 1.30 & & 0.963 & 0.004 & & 0.00434 & 0.00023 \\
\hline 1998 & 134 & & 99.2 & 0.2 & & 47.72 & 1.46 & & 0.971 & 0.004 & & 0.00486 & 0.00025 \\
\hline Type of birth (T) & & 0.71 & & & 0.78 & & & 0.04 & & & 0.00 & & \\
\hline Single & 829 & & 98.8 & 0.2 & & 43.60 & 1.40 & & 0.948 & 0.004 & & 5.22 & 0.24 \\
\hline Twin & 764 & & 98.9 & 0.1 & & 44.36 & 1.09 & & 0.955 & 0.003 & & 3.77 & 0.19 \\
\hline$\geq$ Triplet & 100 & & 99.0 & 0.2 & & 44.82 & 1.66 & & 0.962 & 0.005 & & 3.59 & 0.29 \\
\hline$\underline{\text { Dam age }}$ (DA) & & 0.10 & & & 0.07 & & & 0.88 & . & & 0.09 & & \\
\hline 1 & 284 & & 98.7 & 0.2 & & 46.06 & 1.36 & & 0.955 & 0.004 & & 0.00390 & 0.00024 \\
\hline 2 & 683 & & 98.9 & 0.1 & & 43.96 & 1.06 & & 0.955 & 0.003 & & 0.00445 & 0.00018 \\
\hline 3 & 500 & & 98.7 & 0.2 & & 41.82 & 1.38 & & 0.957 & 0.004 & & 0.00403 & 0.00024 \\
\hline 4 & 226 & & 99.4 & 0.3 & & 45.19 & 2.21 & & 0.952 & 0.006 & & 0.00439 & 0.00038 \\
\hline No. of weights ( $N$ & NOW) & 0.13 & & & 0.00 & & & 0.00 & & & 0.00 & & \\
\hline $12.15 \mathrm{WT}$ & 266 & & 98.8 & 0.2 & & 40.60 & 1.60 & & 0.974 & 0.005 & & 5.04 & 0.28 \\
\hline$>15 \mathrm{WT}$ & 1427 & & 99.1 & 0.1 & & 47.92 & 0.86 & & 0.936 & 0.002 & & 3.34 & 0.15 \\
\hline
\end{tabular}

The $\mathrm{R}^{2}$ estimate was $98.9 \%$, indicating that Brody's function is a statistically acceptable model for describing the growth curve of the studied sample of sheep. 
This is in agreement with Elshennawy et al. (1998) in their study on crosses with Finnsheep.

Romanov and its crossbreds with Rahmani sheep had similar $(P>0.05)$ growth parameters.

The effect of sex was highly significant $(\mathrm{P}<0.01)$ on $\mathrm{A}$ and $\mathrm{B}$ but not significant $(P>0.05)$ on $\mathrm{K}$. Males had higher estimates of weight at maturity and at the initial life stages.

Season of birth did not seem to affect $A$ or $K$ significantly $(P>0.05)$. It had significant effect on B. Lambs born in autumn showed higher initial weight changes than those born in spring or summer.

Year of birth affected $\mathrm{A}, \mathrm{B}$ and $\mathrm{K}$ significantly $(\mathrm{P}<0.0001)$. The $\mathrm{A}$ and $\mathrm{B}$ estimates showed initial drops but late improvement with progress of years of the experiment. The $\mathrm{K}$ values showed a trend of increase with years.

The effect of type of birth was not significant $(\mathrm{P}>0.05)$ on $\mathrm{A}$, significant $(\mathrm{P}<0.05)$ on $\mathrm{B}$ and significant $(\mathrm{P}<0.01)$ on $\mathrm{K}$. Born lambs as twin and triplet realized higher estimates of weight at maturity and at early life stages than that of lambs born as single.

Dam age had not significant $(P>0.05)$ effect on the considered growth parameters.

The relative magnitudes of the components of variance for breed groups, sex, season of birth, year of birth, type of birth, age of the dam and number of observec weights are presented in Figure 2 for A, B and K. As expected, number of observer weights is the major source of variation in all growth parameters. Specifically, larg: contributions were noticed for sex in differences in $\mathrm{A}$, for year of birth in the variation in $B$ and for type of birth in the variation of $K$.

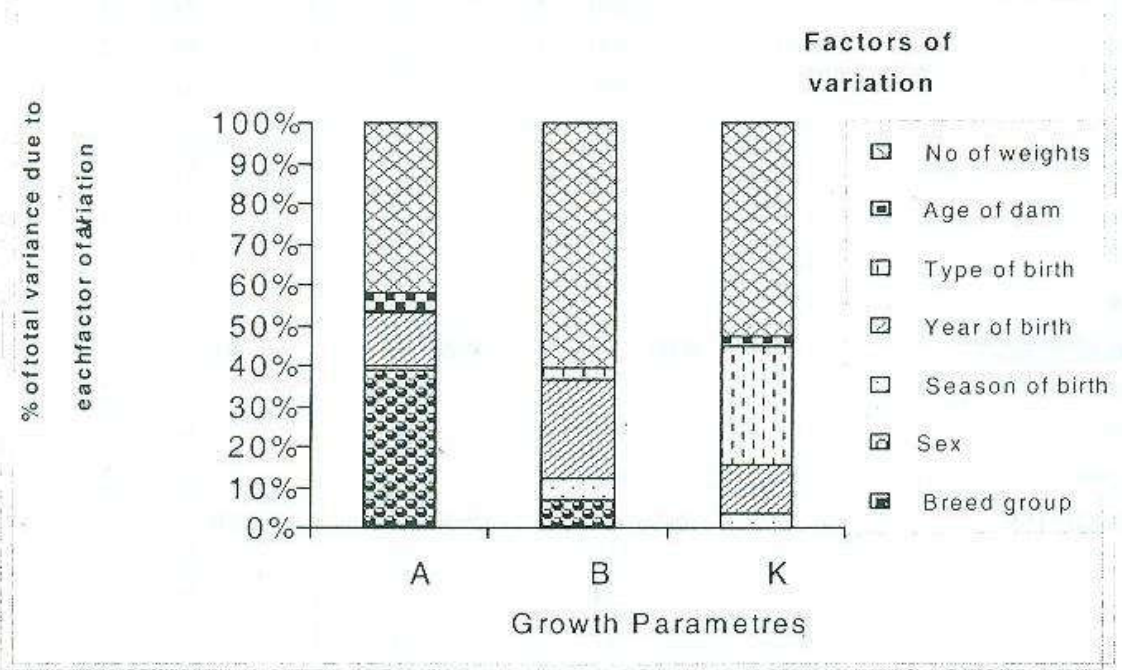

Figure 2. Partitioning of total variance into that attributable to breed group, sex, season of birth, year of birth, type of birth, age of the dam and number of observed weights

Instantaneous growth rate:

The mean least-squares estimates for the main factors affecting IGR, are presented 
in Table 3.

Table 3. The probability of type I error (P), least squares means (LSM) and their standard errors (SE) computed of the main factors affecting the instantaneous growth rate (g) at 2 (IGR2), 6 (IGR6) and 12 (IGR12) months of age

\begin{tabular}{|c|c|c|c|c|c|c|c|c|c|c|}
\hline \multirow[t]{2}{*}{ Factor } & \multirow[t]{2}{*}{ No. } & \multicolumn{3}{|c|}{ IGR2 } & \multicolumn{3}{|c|}{ IGR6 } & \multicolumn{3}{|c|}{ IGR12 } \\
\hline & & $\mathbf{P}$ & LSM & SE & $P$ & LSM & $\mathrm{SE}$ & $\mathrm{P}$ & LSM & $\mathrm{SE}$ \\
\hline$\mu$ & 1693 & & 118 & 5 & & 69 & 2 & & 35 & 2 \\
\hline Breed group (BR) & & 0.10 & & & 0.02 & & & 0.60 & & \\
\hline Romanov & 136 & & 118 & 6 & & 69 & 3 & & 35 & 3 \\
\hline 1/2Romanov & 782 & & 114 & 3 & & 68 & 1 & & 35 & 1 \\
\hline 1/4Romanov & 775 & & 122 & 3 & & 72 & 1 & & 36 & 1 \\
\hline$\underline{\operatorname{Sex}}(S)$ & & 0.00 & & & 0.00 & & & 0.00 & & \\
\hline Male & 763 & & 126 & 3 & & 75 & 1 & & 38 & 1 \\
\hline Female & 930 & & 110 & 3 & & 64 & 1 & & 33 & 1 \\
\hline Season of birth (SN) & & 0.08 & & & 0.02 & & & 0.06 & & \\
\hline Feb. & 744 & & 120 & 3 & & 68 & 1 & & 33 & $i$ \\
\hline June & 533 & & 112 & 4 & & 69 & 2 & & 37 & 2 \\
\hline Oct. & 386 & & 122 & 4 & & 72 & 2 & & 36 & 2 \\
\hline Year of birth $(Y)$ & & 0.00 & & & 0.00 & & & 0.00 & & \\
\hline 1983 & 38 & & 110 & 6 & & 76 & 3 & & 45 & 3 \\
\hline 1984 & 74 & & 134 & 5 & & 68 & 2 & & 29 & 2 \\
\hline 1985 & 47 & & 116 & 6 & & 77 & 2 & & 43 & 2 \\
\hline 1986 & 137 & & 127 & 4 & & 71 & 2 & & 32 & 2 \\
\hline 1987 & 67 & & 111 & 5 & & 68 & 2 & & 35 & 2 \\
\hline 1988 & 141 & & 98 & 4 & & 61 & 2 & & 33 & 2 \\
\hline 1989 & 69 & & 99 & 5 & & 63 & 2 & & 35 & 2 \\
\hline 1990 & 85 & & 104 & 4 & & 61 & 2 & & 33 & 2 \\
\hline 1991 & 78 & & 116 & 5 & & 66 & 2 & & 32 & 2 \\
\hline 1992 & 184 & & 100 & 3 & & 67 & 1 & & 39 & 2 \\
\hline 1993 & 87 & & 108 & 5 & & 65 & 2 & & 34 & 2 \\
\hline 1994 & 151 & & 129 & 3 & & 71 & 1 & & 33 & 2 \\
\hline 1995 & 102 & & 133 & 4 & & 72 & 2 & & 31 & 2 \\
\hline 1996 & 148 & & 128 & 4 & & 71 & 2 & & 33 & 2 \\
\hline 1997 & 151 & & 131 & 3 & & 76 & 1 & & 37 & 1 \\
\hline 1998 & 134 & & 142 & 4 & & 80 & 2 & & 38 & 2 \\
\hline Type of birth (T) & & 0.00 & & & 0.20 & & & 0.01 & & \\
\hline Single & 829 & & 135 & 4 & & 71 & 1 & & 32 & 2 \\
\hline Twin & 764 & & 111 & 3 & & 69 & 1 & & 36 & 1 \\
\hline$\geq$ Triplet & 100 & & 108 & 4 & & 69 & 2 & & 38 & 2 \\
\hline Dam age (DA) & & 0.00 & & & 0.05 & & & 0.20 & & \\
\hline I & 284 & & 116 & 3 & & 71 & 1 & & 37 & 2 \\
\hline 2 & 683 & & 124 & 3 & & 71 & 1 & & 35 & 1 \\
\hline 3 & 500 & & 112 & 3 & & 67 & 1 & & 34 & 2 \\
\hline 4 & 226 & & 120 & 6 & & 70 & 2 & & 35 & 2 \\
\hline No. of weights (NOW) & & 0.00 & & & 0.24 & & & 0.00 & & \\
\hline $12-15 \mathrm{WT}$ & 266 & & 128 & 4 & & 69 & 2 & & 31 & 2 \\
\hline$>15 \mathrm{WT}$ & 1427 & & 108 & 2 & & 71 & 1 & & 40 & 1 \\
\hline
\end{tabular}


It seems that the increase in Romanov blood together with the decrease in Rahmani blood would adversely affect IGR, The results of IGR of Rahmani sheep (0\% Romanov) reported by Elshennawy et al. (1993) were much higher than those obtained in the present work on $75 \%$ Rahmani $+25 \%$ Romanov which, in turn, were significantly higher than those recorded for $50 \%$ Rahmani $+50 \%$ Romanov. Decrease in adaptability to heat stress, exposure to solar radiation under extensive or semi extensive rearing systems may be responsible for the disadvantageous growth results of exotic breeds and crossbreds in the region (Hassan, 1991).

The instantaneous growth rate at all concerned ages was affected significantly $(\mathrm{P}<0.01)$ by sex. The higher estimates of instantaneours growth rate were observed for males than for females.

Season of birth had significant effect (P<0.05) on IGR6 and non significant on IGR2 and IGR12. Lambs born in autumn exhibited higher IGR2 and IGR6 than those born in spring or summer.

The influence of year of birth was significant $(\mathrm{P}<0.01)$ on instantaneous growth rate at all ages. The estimates of instantaneous growth rates did not show any specific trend through the years but they showed a pattern of increasing values with the last three years of the experiment.

The effect of type of birth was significant on IGR2 $(\mathrm{P}<0.01)$ and IGR12 $(P<0.05)$. Single lambs gave higher estimates of IGR2 and IGR6 than that of twin and triplet lambs, while opposite results were observed with IGR 12.

Dam age seemed to affect IGR2 $(\mathrm{P}<0.01)$ and IGR6 $(\mathrm{P}<0.05)$. It had non significant effect $(P>0.05)$ on IGR12. IGR6 and IGR12 recorded higher $(P<0.05)$ estimates for born lambs of young dams than for born lambs of old dams.

\section{Amount of maturity remaining to be attained:}

The mean least-squares estimates for the main factors affecting $\mathrm{AMRA}_{t}$ are presented in Table 4.

The effect of breed group was non significant $(P>0.05)$ on amount of maturity at all ages. The estimate of AMRA2 was slightly higher for Romanov than for $1 / 2$ Romanov and $1 / 4$ Romanov (Table 4). No significant differences $(P>0.05)$ were observed for amount of maturity at all ages between males and females. Nevertheless, amount of maturity at 2 months of age was slightly higher for males than that for females.

The effect of season of birth was significant $(\mathrm{P}<0.05)$ on AMRA2 and non significant $(P>0.05)$ on AMRA6 and AMRA12. Lambs born in summer showed a trend of higher amount of maturity at all studied stages than lambs born in spring and autumn.

Year of birth affected AMRA at all ages significantly $(\mathrm{P}<0.01)$. Fluctuant estimates of AMRA at all ages were observed through the years of the experiment.

The estimates of amount of maturity were significantly $(\mathrm{P}<0.01)$ affected by type of birth. The AMRA at all ages for single lambs was lower than that for twin and triplet lambs.

The effect of dam age was significant $(\mathrm{P}<0.05)$ on AMRA2 and non significant ( $>>0.05$ ) on both AMRA6 and AMRA12.

Higher estimates of amount of maturity attained at 2,6 and 12 months of age were observed for progeny of young ewes than for those of old ewes. 
Table 4. The probability of type I error (P), least squares means (LSM) and their standard errors (SE) computed of the main factors affecting the amount of maturity remaining to be attained (AMRA) at 2 (AMRA2), 6 (AMRA6) and 12 (AMRA12) months of age

\begin{tabular}{|c|c|c|c|c|c|c|c|c|c|c|}
\hline \multirow[t]{2}{*}{ Factor } & \multirow[t]{2}{*}{ No. } & \multicolumn{3}{|c|}{ AMRA2 } & \multicolumn{3}{|c|}{ AMRA6 } & \multicolumn{3}{|c|}{ AMRA12 } \\
\hline & & $\mathrm{P}$ & LSM & SE & $\mathrm{P}$ & LSM & SE & $\mathrm{P}$ & LSM & $\mathrm{SE}$ \\
\hline$\mu$ & 1693 & & 3.82 & 0.23 & & 1.22 & 0.09 & & 0.47 & 0.02 \\
\hline Breed group (BR) & & 0.68 & & & 0.67 & & & 0.49 & & \\
\hline Romanov & 136 & & 3.91 & 0.36 & & 1.25 & 0.16 & & 0.49 & 0.08 \\
\hline 1/2Romanov & 782 & & 3.86 & 0.16 & & 1.26 & 0.07 & & 0.50 & 0.03 \\
\hline 1/4Romanov & 775 & & 3.69 & 0.15 & & 1.16 & 0.06 & & 0.44 & 0.03 \\
\hline$\underline{\operatorname{Sex}}(\mathrm{S})$ & & 0.73 & & & 0.99 & & & 0.89 & & \\
\hline Male & 763 & & 3.86 & 0.17 & & 1.23 & 0.07 & & 0.48 & 0.04 \\
\hline Female & 930 & & 3.79 & 0.19 & & 1.23 & 0.08 & & 0.49 & 0.04 \\
\hline Season of birth (SN) & & 0.04 & & & 0.12 & & & 0.15 & & \\
\hline Feb. & 744 & & 3.54 & 0.15 & & 1.15 & 0.07 & & 0.46 & 0.04 \\
\hline June & 533 & & 4.11 & 0.24 & & 1.37 & 0.10 & & 0.55 & 0.05 \\
\hline Oct. & 386 & & 3.82 & 0.23 & & 1.17 & 0.10 & & 0.44 & 0.05 \\
\hline Year of birth $(Y)$ & & 0.00 & & & 0.00 & & & 0.00 & & \\
\hline 1983 & 38 & & 4.27 & 0.37 & & 1.50 & 0.16 & & 0.63 & 0.08 \\
\hline 1984 & 74 & & 3.03 & 0.27 & & 0.93 & 0.12 & & 0.35 & 0.06 \\
\hline 1985 & 47 & & 4.37 & 0.33 & & 1.41 & 0.15 & & 0.56 & 0.08 \\
\hline 1986 & 137 & & 3.48 & 0.22 & & 0.99 & 0.10 & & 0.35 & 0.05 \\
\hline 1987 & 67 & & 4.08 & 0.30 & & 1.30 & 0.13 & & 0.50 & 0.07 \\
\hline 1988 & 141 & & 3.84 & 0.22 & & 1.32 & 0.10 & & 0.54 & 0.05 \\
\hline 1989 & 69 & & 4.21 & 0.30 & & 1.36 & 0.13 & & 0.54 & 0.07 \\
\hline 1990 & 85 & & 3.82 & 0.25 & & 1.48 & 0.11 & & 0.67 & 0.06 \\
\hline 1991 & 78 & & 3.60 & 0.29 & & 1.13 & 0.13 & & 0.44 & 0.07 \\
\hline 1992 & 184 & & 4.37 & 0.21 & & 1.60 & 0.09 & & 0.70 & 0.05 \\
\hline 1993 & 87 & & 3.80 & 0.28 & & 1.28 & 0.13 & & 0.52 & 0.07 \\
\hline 1994 & 151 & & 3.79 & 0.20 & & 1.07 & 0.09 & & 0.38 & 0.05 \\
\hline 1995 & 102 & & 3.53 & 0.23 & & 0.97 & 0.10 & & 0.33 & 0.05 \\
\hline 1996 & 148 & & 3.60 & 0.21 & & 1.07 & 0.09 & & 0.39 & 0.05 \\
\hline 1997 & 151 & & 3.81 & 0.19 & & 1.19 & 0.09 & & 0.45 & 0.04 \\
\hline 1998 & 134 & & 3.57 & 0.22 & & 1.06 & 0.10 & & 0.38 & 0.05 \\
\hline Type of birth (T) & & 0.00 & & & 0.00 & & & 0.00 & & \\
\hline Single & 829 & & 3.04 & 0.21 & & 0.93 & 0.09 & & 0.34 & 0.05 \\
\hline Twin & 764 & & 4.01 & 0.16 & & 1.33 & 0.07 & & 0.53 & 0.04 \\
\hline$\geq$ Triplet & 100 & & 4.42 & 0.25 & & 1.43 & 0.11 & & 0.58 & 0.06 \\
\hline Dam age (DA) & & 0.03 & & & 0.09 & & & 0.16 & & \\
\hline 1 & 284 & & 4.09 & 0.20 & & 1.34 & 0.09 & & 0.53 & 0.05 \\
\hline 2 & 683 & & 3.51 & 0.16 & & 1.11 & 0.07 & & 0.43 & 0.04 \\
\hline 3 & 500 & & 3.87 & 0.21 & & 1.23 & 0.09 & & 0.48 & 0.05 \\
\hline 4 & 226 & & 3.82 & 0.33 & & 1.24 & 0.15 & & 0.49 & 0.08 \\
\hline No. of weights (NOW) & & 0.02 & & & 0.00 & & & 0.00 & & \\
\hline $12-15 \mathrm{WT}$ & 266 & & 3.56 & 0.24 & & 1.02 & 0.11 & & 0.37 & 0.05 \\
\hline$>15 \mathrm{WT}$ & 1427 & & 4.08 & 0.13 & & 1.44 & 0.06 & & 0.60 & 0.03 \\
\hline
\end{tabular}


Egyptian J. Anim. Prod. (2004)

\section{CONCLUSION}

With the increase of Romanov blood from $25 \%$ to $50 \%$ then to $100 \%$ almost no significant change has happened in mature weight, rate of maturity and instantaneous growth rates at 2,6 and 12 months of age. For these growth characteristics, more or less distinguished patterns were noticed between males and females and between single and non-single born lambs. With progress of years of experiment, some improvement in growth-related traits has been noticed.

\section{ACKNOWLEDGEMENT}

The authors are grateful to Dr. E.S.E. Galal for his criticism of the work.

\section{REFERENCES}

Brody, S., 1945. Bioenergetics and Growth. Rheinhold Pub. Corp., New York.

Brown, J. E., C. J. Brown and W. T. Butts, 1972. A discussion of the genetic aspects of weight, mature weight and rate of maturing in Hereford and Angus cattle. J. Anim. Sci., 34:525-537.

Brown, J. E., H. A. Fitzhugh and T.C. Cartwright, 1976. A comparison of nonlinear models for describing weight age relationship in cattle. J. Anim. Sci., 42:810-818.

Elshennawy, M. A., H. Mansour and E. El-Tawil, 1993. Estimation of asymptotic weight and growth parameters for Egyptian Rahmani and Ossimi sheep breeds and their crosses with Finnsheep. The $10^{\text {th }}$ Conference of the Egyptian Society of Animal Production, 13-15 December, 1998. Assiut, Egypt. 522-529.

El-Wakil, S. I. K. 2004. A study of growth function on the Egyptian Barki sheep. M.Sc. thesis, Faculty of Agriculture, Ain Shams University, Cairo, Egypt.

Harvey, W.R., 1990. User's guide for LSMLMW and MIXMDL, Least- Squares and Maximum Likelihood Computer Program. The Ohio State University, Columbus (Mimeo).

Hassan, Ferial, 1991. Constraints of introducing exotic breeds in north Africa. Proceeding of a workshop on the Improvement of Small Ruminant Production in North Africa, 3-7 June, Cairo, Egypt.

McCurley, J.R., W.T. Butts and K.P. Bovard. 1984. Growth patterns of Angus, Hereford and Shorthorn cattle. I. Comparison of inbred and noninbred lines, changes in patterns over time and effects of level of inbreeding and reproduction performance. J. Anim. Sci. 59:1194-1204.

Mokhtar, M. M., H. Mansour, A. Younis and H. El-Gabbas, 1991. Growth and mature size in fat-tailed Barki sheep. Egyp. J. Anim. Prod., 28:41-48.

Mousa, E., 1989. Phenotypic and genetic variation in lambs growth. M.Sc. Thesis, University of Assiut, Egypt.

SAS, 1987. SAS User's Guide: Statistics. SAS Inst., Inc, Cary, NC. 


\title{
خصائص نمو الحملان من الرومانوف وهجن الرومانوف مح الرحمانى فى مصر
}

\author{
محمد عبد الحميد الشناوى'، حازم المهدى"، منى عبد الظظهز عثمان'
}

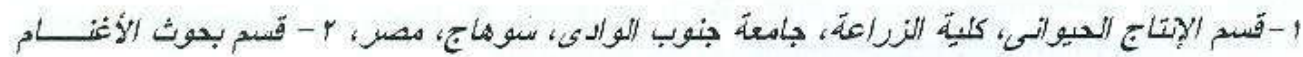

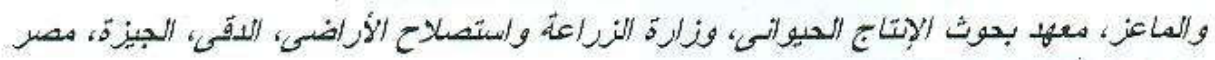

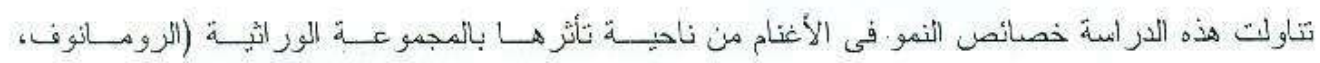

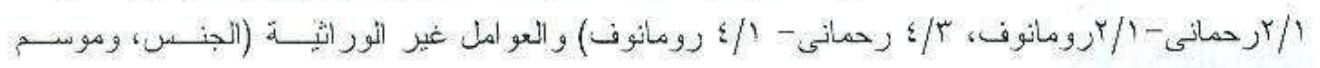

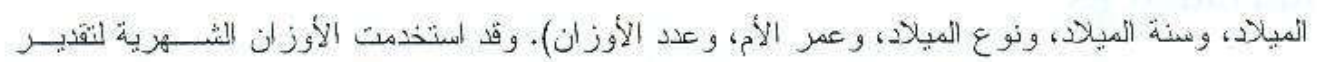

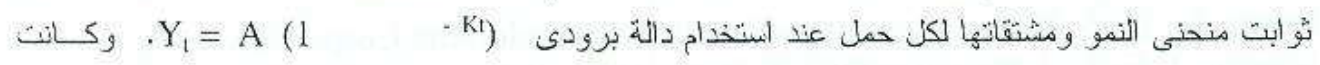
مثو سطات مجموع المربعات الدنيا لثو ابت منحنى النمو هى

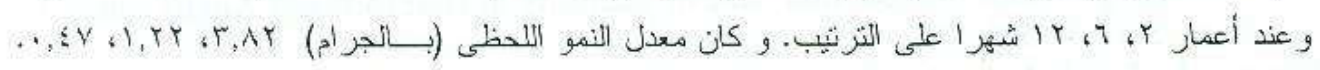

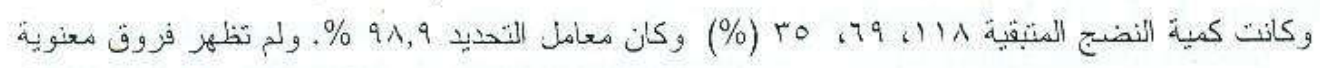

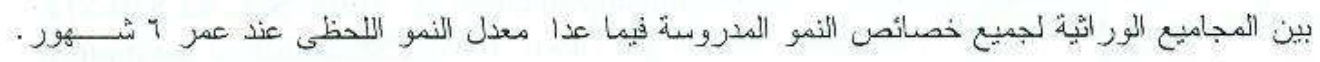

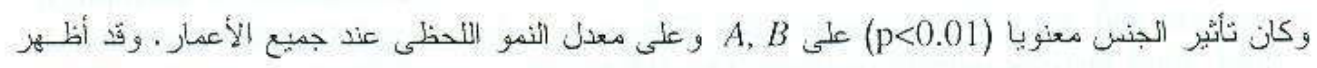

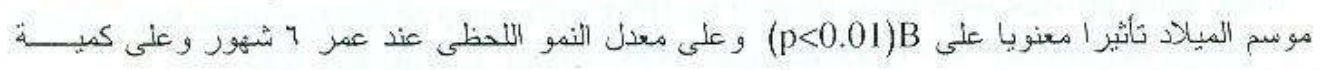

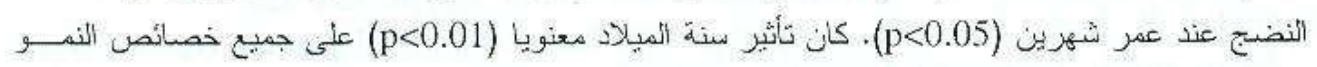

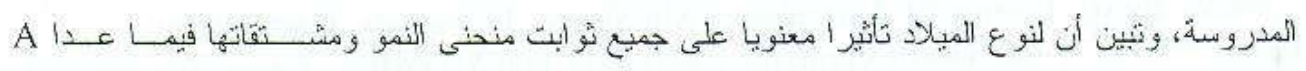

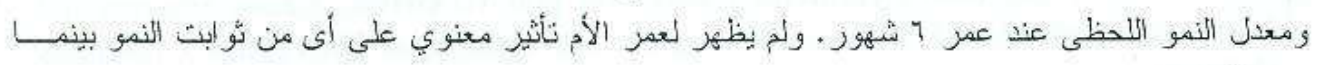

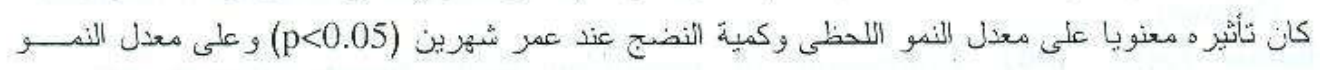

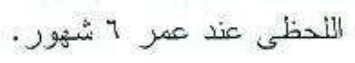

